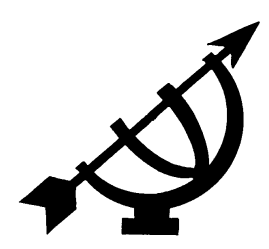

\title{
Systematic perspectives on diverging mathematical orientations ${ }^{1}$
}

\author{
D.F.M. Strauss \\ Faculty of Humanities \\ University of the Free State \\ BLOEMFONTEIN \\ E-mail:dfms@cknet.co.za
}

It is recommendable to consider the distinction between the 'arithmetical' and 'geometrical' intuition not according to the moments of the spatial and temporal, but with a view to the difference between what is discrete and what is continuous. ${ }^{2}$

\begin{abstract}
Systematic perspectives on diverging mathematical orientations

The popular view that mathematics is "objective" and "neutral" in the sense that it does not know different standpoints is contradicted by the factual state of modern mathematics. In the light of the dominant one-sided trends in the history of mathematics, fluctuating between arithmeticism and a geometrisation of this discipline, this article explores some provisional startingpoints for a different view. This third option is explored by investigating some features of an acknowledgement of the
\end{abstract}

1 I want to thank two mathematicians - Proff. B. de la Rosa and H. Bargenda for many valuable suggestions made during thorough-going discussions of the text of an earlier version of this article.

2 'Es empfiehlt sich, die Unterscheidung von 'arithmetischer' und 'geometrischer' Anschauung nicht nach den Momenten des Räumlichen und Zeitlichen, sondern im Hinblick auf den Unterschied des Diskreten und Kontinuierlichen vorzunehmen" (Bernays, 1976:81) . 
uniqueness of number and space without neglecting the interaspectual connections between these two modal functions. An argument is advanced regarding the inevitability of employing analogical (or elementary) basic concepts, and this perspective is articulated in terms of the theory of modal aspects. Numerical and spatial terms are discussed and eventually focused on a deepened understanding of the meaning of infinity. In addition to a brief look at the circularity present in the arithmeticist claim that mathematics could be fully arithmetised (Grünbaum), attention is also asked for the agreement between Aristotle and Cantor regarding the nature of continuity - assessed in terms of the irreducibility of the numerical and spatial aspects of reality. Finally a characterisation is given of the ontological assumptions of intuitionism and axiomatic formalism.

\section{Opsomming}

\section{Sistematiese perspektiewe op uiteenlopende wiskundige oriënterings}

Die populêre opvatting dat die wiskunde "objektief" en "neutraal" is in die sin dat dit geen standpuntverskille impliseer nie, word weerspreek deur die feitelike stand van sake in die moderne wiskunde. In die lig van die dominante eensydige strominge in die geskiedenis van die wiskunde wat gefluktueer het tussen die aritmetisisme en 'n geometrisering van hierdie dissipline, belig hierdie artikel enkele aanknopingspunte vir 'n derde opsie. Hierdie derde opsie word aangepak deur sommige eienskappe van die erkenning van die uniekheid van getal en ruimte te ondersoek, sonder om die intermodale skakels tussen hierdie twee aspekte te verwaarloos. 'n Beredeneringslyn word ontwikkel ten opsigte van die onvermydelike gebruik van analogiese (of elementêre) grondbegrippe en hierdie perspektief word dan geartikuleer in terme van die teorie van modale aspekte. Getals- en ruimteterme word bespreek en uiteindelik toegespits op 'n verdiepte verstaan van die sin van die oneindige. Bykomend tot 'n oorsigtelike weergawe van die redes waarom 'n onhoudbare sirkelredenasie opges/uit lê in die vermeende aritmetisering van die wiskunde (Grünbaum), word ook aandag gevra vir die ooreenkoms en verskil tussen Aristoteles and Cantor aangaande die aard van kontinuïteit beoordeel in terme van die onherleidbaarheid van die getals- en ruimteaspekte van die werklikheid. Ten slotte word die intuïsionistiese wiskunde en die aksiomatiese versamelingsleer getipeer aan die hand van hul onderskeie ontologiese vooronderstellings. 


\section{Introductory remark}

It is a widely accepted and popular conviction that mathematics is an exact science that represents the acme of sound reasoning. Although there may be differences of opinion regarding diverging views of mathematics (or philosophies of mathematics), this popular view holds that intrinsically mathematics is objective and neutral.

In his work on Zeno's Paradoxes Salmon, for example, merely refers to "intuitionistic philosophers of mathematics" - without acknowledging the truly mathematical character of this trend in 20th century mathematics (see Salmon, 2001:23 - he refers to Körner's work The Philosophy of Mathematics, 1968). By contrast, Stegmüller (1970:331) remarks:

The special character of intuitionistic mathematics is expressed in a series of theorems that contradict the classical results. For instance, while in classical mathematics only a small part of the real functions are uniformly continuous, in intuitionistic mathematics the principle holds that any function that is definable at all is uniformly continuous.

Beth (1965:89) also highlights this point:

It is clear that intuitionistic mathematics is not merely that part of classical mathematics which would remain if one removed certain methods not acceptable to the intuitionists. On the contrary, intuitionistic mathematics replaces those methods by other ones that lead to results which find no counterpart in classical mathematics.

One may also mention Hilbert's appreciation of Cantor's transfinite number theory - expressed in his remark that no one will ever drive us out of the paradise created by Cantor (Hilbert, 1925:170), and contrasting it with the intuitionist Heyting who disqualified transfinite number theory as a phantasm (Heyting, 1949:4).

If it is therefore true that the discipline of mathematics has not escaped from an inner split, manifest in diverging orientations, the basic (philosophical) problem is: how is it possible to explain opposing orientations within this basic scholarly discipline?

In our analyses below it will be attempted to provide an answer to this question. 


\section{Basic structural features}

The view of Bernays quoted at the beginning of the article actually captures the entire history of mathematics, because alternative views on the relationship of discreteness and continuity resulted in diverging systematic orientations.

In a preceding article on "Primitive terms in mathematics" (cf. Strauss, 2005a:515-534) the following aspects have been discussed briefly:

- The role of key terms - such as order, succession, induction, infinity (endlessness), at once, wholeness (totality), the wholeparts relation and (infinite) divisibility.

- In addition to the basic role of multiplicity within logic (and mathematics) the connection with basic concepts such as constants and variables was also highlighted.

- It has been argued that the various disciplines do have to account for the sense in which they employ their basic concepts. It turned out that this issue is intimately connected to the primitive terms encountered within scholarly disciplines.

- An alternative way to look at these foundational problems is to relate them to the problem of unity and diversity. It concerns the way in which an account is given of the coherence of irreducibiles.

The mathematician Rucker emphasises the same intuition as the one highlighted by Bernays: "The discrete and continuous represent fundamentally different aspects of the mathematical universe" (Rucker, 1982:243). Moore expands the context of these considerations by discerning two "clusters" of concepts that dominate the history of the notion of infinity.

- In the first cluster the following terms are found: "boundlessness; endlessness; unlimitedness; immeasurability; eternity; that which is such that, given any determinate part of it, there is always more to come; that which is greater than any assignable quantity" (Moore, 1990:1).

- Within the second cluster he captures terms like completeness; wholeness; unity; universality; absoluteness; perfection; selfsufficiency; autonomy (Moore, 1990:1-2). 
These characterisations are congruent with the weak spot alluded to by Fraenkel et al. - regarding the "the gap between discrete and continuous" (Fraenkel et. al., 1973:212-213). On the previous page these authors present a stronger formulation:

Bridging the gap between the domains of discreteness and of continuity, or between arithmetic and geometry, is a central, presumably even the central problem of the foundation of mathematics (Fraenkel et al., 1973:211) ${ }^{3}$.

Although this formulation is consistent with the history of the problem - that has explored the one-sided extremes of reducing number to space or reducing space to number - it will turn out that a fruitful alternative will have to do two important things:

- acknowledge the difference between discreteness and continuity; and

- holding on to the mutual inter-connectedness of both of these perspectives.

An attempt to explore this alternative approach, however, requires distinctions that are not known within the distinct scholarly disciplines. The guiding perspective that is required is found in an analysis of the analogical basic concepts employed by the various disciplines. What is truly remarkable in this context is that although it is not acknowledged as such, every academic discipline implicitly or explicitly has to use basic (analogical) concepts.

\section{The inevitability of employing analogical elementary basic concepts}

The contemporary fad of postmodernism explores language as horizon, but in doing that it does not sufficiently distinguish between two basic kinds of analogies, namely between (i) entitary analogies and (ii) modal analogies. 4 Ordinary and scientific language designate analogies between entities with metaphors (such as the foot of the mountain or the wave theory of light). Whereas such

3 In her discussion of set theory as a foundation for mathematics Maddy prefers to follow in the footsteps of the Zermelo-Fraenkel axiomatisation of mathematics (see Maddy, 1997:14, 39 ff., 47 ff.).

4 For a more detailed analysis of the similarities and differences between analogical basic concepts and metaphors as well as the foundational position of concept formation in relation to lingual signs (words), see Strauss (2005b:1-20). 
metaphors (entitary analogies) could be replaced by entirely different ones, the substitution of modal analogies is only meaningful if synonomous terms are employed. A spatial term such as domain, for example, could be replaced by others, such as range, scope or sphere. Although, for technical purposes, mathematicians may decide to attach slightly different connotations to these different terms they all still share a generic spatial meaning that cannot be denied. In order to understand what is involved in the use of truly analogical basic concepts, the classical legacy concerning the infinite divisibility of continuity is particularly instructive.

\section{- Mathematical space and physical space}

In an article commemorating the centenary of Karl Weierstrass (published in 1925), Hilbert looks at this issue from the perspective of the infinitely small and the infinitely large (Hilbert, 1925:163 ff.). The discovery of quanta of energy on the one hand, and Einstein's theory of relativity, on the other hand, eliminates both possibilities. A more extensive explanation is found in his oration on Naturerkennen und Logik (Hilbert, 1930:380-381).

In order to account for the discrete nature of the omission or absorbtion of energy, Planck postulated that radiant energy is quantised, proportional to the frequency $v$ in the formula $\mathrm{E}=h n v-$ where $n$ is an integer, $v$ the frequency, and $h$ the quantum of action (Wirkungsquantum) with the value $6.624 \times 10^{-34}$. This postulation implies that one has to distinguish between mathematical space on the one hand, and physical space on the other. Whereas mathematical space - in a purely abstract and functional perspective - is both continuous and infinitely divisible, physical space is neither continuous nor infinitely divisible. Bound to the quantum structure of energy, physical space cannot be subdivided ad infinitum. Energy quanta indeed represent the limit of the divisibility of energy. 5

This example demonstrates that an analogy is found whenever differences are shown in what is similar. In the case of our example one can easily observe that both mathematical space and physical space are extended (their similarity). Yet, in being discontinuous and not infinitely divisible (the differences between them) the latter is not the same as the former.

5 Owing to gravitation ("curved space") the universe is considered to be finite although unbounded. 
Our concept of physical space is an instance of an analogical basic concept. This basic concept accounts for the fact that within the structure of the physical aspect, the meaning of space is analogically reflected. The multiplicity of properties combined in the unity of a (logical) concept, in turn, analogically reflects the meaning of number (the one and the many) within the logical-analytical aspect of reality. In general, each aspect of reality expresses its coherence with the other aspects through analogical moments such as these.

The Dutch philosopher, Herman Dooyeweerd, created a unique theory of "modal law-spheres" in order to explain this complex state of affairs. The classical distinction between properties and entities runs parallel to that between function and entity. ${ }^{6}$ The basic idea is that entities function within the various aspects of reality.

\section{- Nominalistic assumptions}

For an understanding of different mathematical orientations this perspective is indeed decisive. The long-standing metaphysical legacy of the West after the Renaissance, in what is known as its nominalistic trends, denies the reality (i.e. ontic existence) of these aspects of reality. Every form of universality (universals) is considered to be mere modes of thought. Since Descartes this nominalistic assumption ${ }^{7}$ accompanied the understanding of

6 In Cassirer (1953) a significant contribution to an understanding of this issue is found. Frequently concepts of function are also designated as concepts of relation ("Relationsbegriffe").

7 The classical realist position in philosophy accepts a threefold existence of the so-called "universalia": ante rem in God's mind (the legacy of Plato's transcendent ideal forms), in re within things (a la Aristotle - as their universal substantial forms), and post rem (as subjective universal concepts - with as criterion of truth the correspondence between thought and reality (adequatio intellectus et rei). Nominalism rejects the first two and only acknowledges universal concepts (or words) within the human mind - outside the human mind only uniquely individual entities exist. (Within nominalism a distinction is made between those nominalists who accept universal concepts: conceptualism. and the more extreme position which only accepts words.) In their ordinary understanding sets are universals and therefore they partake, in the words of Fraenkel et al. (1973:332), in "the well-known and amply discussed classical problem of the ontological status of the universals". The three main traditional answers given to this problem, namely realism, nominalism and conceptualism, are related with their contemporary counter-parts known as platonism, neonominalism, and neo-conceptualism (Fraenkel et al., 1973:332). Stegmüller explains the mathematical relevance of these different positions as follows: The 
functional (modal) aspects. In his Principles of Philosophy Descartes explicitly says "that number and all universals are only modes of thought" (Part I, LVIII; see Descartes, 1965a:187). Hilbert (implicitly) continues this orientation when he argues that after we have established that reality is finite in two directions (the infinitely small and the infinitely large), the infinite may still have a justified place within our thinking! 8 The implication is clear: "reality" is exhausted by entities (usually referred to as objects), modal (functional) properties are located in the realm of thought.

Once this mistaken (nominalistic) view on the nature of mathematics has permeated philosophical discussions it is difficult to escape from its grip. Shapiro recently provides us with a typical formulation in his discussion of ideas of Quine when he refers to the "abstract, nonspatiotemporal nature of mathematical objects" (Shapiro, 2005a:15). In an earlier work he mentions the challenge to realism that "needs an account of the relationship between the eternal, acausal, detached mathematical universe and the subject matter of science and everyday language - the material world" (Shapiro, 1997:4-5).

The theory of modal aspects escapes from this way in which the problem is formulated by introducing the idea that the aspects of reality are really (ontic) aspects of reality. The argument followed in this article will be that the diverging standpoints within mathematics arise from alterative (and even mutually exclusive) views on the inter-connections between various ontically given aspects.

\section{The theory of modal aspects}

The theory of modal law-spheres first of all argues for the ontic status of the various modal aspects. Hao Wang remarks that Gödel is very "fond of an observation that he attributes to Bernays: ... That the flower has five petals is as much part of objective reality as that its color is red" (Wang, 1988:202). The quantitative side (aspect) of things (entities) is not a product of thought - at most human

three mentioned ontological positions, namely nominalism, conceptualism, and platonism, are mapped in terms of the quantitative categories "finite totality (Gesamtheit) - denumerable infinite totality - non-denumerable infinite totality" (Stegmüller, 1965:117-118).

8 "Die Endlichkeit des Wirklichen haben wir nun in zwei Richtungen festgestellt: nach dem Unendlichkleinen und dem Unendlich großen. Dennoch könnte es sehr wohl zutreffen, daß das Unendliche in unserem Denken einen wohlberechtigten Platz hat und die Rolle eines unentbehrlichen Begriffes einnimmt" (Hilbert, 1925:165). 
reflection can explore this given (functional) trait of reality by analysing what is entailed in the meaning of discrete quantity. Yet, in doing this (theoretical and non-theoretical) thought investigates the meaning of the quantitative aspect as it is given.

\section{- The formation of numerals}

Normally the first step is found in the formation of numerals (i.e. number symbols). Saying that numbers are created goes too far, because the quantitative mode of reality is pre-supposed in every construction of numerals (with their implied reference to numbers). The simplest act of counting already explores the ordinal meaning of this quantitative aspect of reality. Frege correctly remarks "that counting itself rests on a one-one correlation, namely between the number-words from 1 to $n$ and the objects of the set" (quoted by Dummett, 1995:144).

However, in the absence of a sound distinction between the dimension of concretely existing entities (normally largely identified with "physical", "space-time existence" or material existence) and the dimension of functional modes (aspects) of ontic reality, which cannot be observed through sensory perception, ${ }^{9}$ mathematicians often struggle to account for the epistemic status of their "subject matter".

\section{- The epistemic status of the "subject matter" of mathematics}

Perhaps the awareness of this need is best articulated in Wang's discussion of Gödel's thought. In his discussion of Gödel's ideas regarding "mathematical objects" Wang mentions Gödel's rejection of Kant's conception regarding the "subjectivity" of mathematical objects. Gödel in contrast holds: "Rather they, too, may represent an aspect of objective reality, but, as opposed to the sensations, their presence in us may be due to another kind of relationship between ourselves and reality" (quoted by Wang, 1988:304, cf. p. 205). To this Wang adds his own support:

9 Frege is convinced that numbers are not sensorily perceptible: "Sinnlich wahrnehmbar und räumlich sind weder diese noch die Brüche, noch die negativen, irrationalen und komplexen Zahlen; und wenn man wirklich nennt, was auf die Sinne wirkt" (Frege, 1884:97). Before him Kant said the same about time: "Nun kann die Zeit für sich nicht wahrgenommen werden" (Kant, 1787:B225). 
I am inclined to agree with Gödel, but do not know how to elaborate his assertions. I used to have trouble by the association of objective existence with having a fixed 'residence' in spacetime. But I now feel that 'an aspect of objective reality' can exist (and be 'perceived by semiperceptions') without its occupying a location in spacetime in the way physical objects do (Wang, 1988:304; cf. Strauss, 2003:69-72).

Of course Wang could have referred to the important insights of Cassirer in this regard. Already in his article on Kant and modern mathematics (Cassirer, 1907), and particularly in his (mentioned) influential work of 1910, Substance and Function (see Cassirer, 1953), Cassirer distinguishes between entities and functions. He clearly realises that the concrete many-sided existence of an individual thing is not exhausted by quantitative properties: "number is to be called universal not because it is contained as a fixed property in every individual, but because it represents a constant condition of judgment concerning every individual as an individual" (Cassirer, 1953:34). If we set aside the (neo-)Kantian undertones of this statement, Cassirer already saw something of what should be called the modal universality of the arithmetical aspect of reality. ${ }^{10}$

\section{- The modal universality of the arithmetical aspect of reality}

The uniqueness of every aspect is guaranteed by its indefinable core (or nuclear) meaning (also designated as its meaning-nucleus). This core meaning qualifies all the analogical meaning-moments within a specific aspect. These analogical moments may refer backwards to aspects that are earlier within the ontic order of aspects (known as retrocipations) or forwards to ontically later aspects (known as anticipations). ${ }^{11}$ The meaning of an aspect

10 The modal universality of an aspect entails that whatever exists within reality (in a concrete sense), in principle has a function within every modal aspect.

11 Earlier and later are understood in the sense of cosmic time as it is called by Dooyeweerd. The aspects of reality are fitted in an inter-modal coherence of earlier and later. The most basic aspect is that of number (meaning-nucleus: discrete quantity), that is followed by the aspect of space (continuous extension), the kinematical aspect (core: constancy), the physical (change/ energy-operation), the biotic (life), the sensitive (feeling), the logical (analysis), the cultural-historical (formative control/power), the sign-mode (symbolical signification), and so on. Cosmic time has an order-side and a duration-side we are acquainted with the numerical time-order of succession, the spatial timeorder of simultaneity, the kinematical time-order of uniform flow, the irreversible physical time-order, the biotical time-order of birth, growth, maturation, aging and dying (cf. Dooyeweerd, 1996-I; 30-32), and so on. 
comes to expression in its coherence with other aspects (i.e. through its retrocipations and anticipations). And it is these retrocipatory analogies that are captured in the elementary basic concepts of a discipline.

\section{- The modal "seat" of particular terms}

The primary challenge to an analysis of the elementary (analogical) basic concepts of the various academic disciplines is given in the identification of the modal "home" or modal "seat" of particular terms. ${ }^{12}$

Within every aspect a difference exists between the order-side (also known as the law-side) and its correlate, the factual side (that which is subjected to the law-side in the sense that it is delimited and determined by the law-side). The numerical time-order of succession belongs to the law-side of the arithmetical aspect, and any ordered sequence of numbers appears at its factual side (think of the natural numbers in their normal succession). With the exception of the numerical aspect (which only has subject-subject relations), all the other aspects in addition also have subject-object relations at their factual side. 13

\section{Numerical and spatial terms}

It is intuitively clear that our awareness of succession and multiplicity (underlying the concept of ordinal numbers and the idea of mathematical induction) makes an appeal to the quantitative aspect of reality. These terms therefore have their modal "seat" (home) within the arithmetical aspect.

Scholars working within different disciplines will always attempt to reduce terms that seem to be primitive to familiar and (presumably) more basic ones. If such an attempt, however, becomes circular, or even worse, contradictory, then the result may be that the primitive terms involved are truly irreducible. Phrased differently: an attempt to define what is indefinable may result in the kind of reduction

12 For example, the one and the many are located within the quantitative aspect, continuity and extension within the spatial aspect, uniform flow and constancy within the kinematic aspect, and so on.

13 The identifiability and distinguishability of something represents its latent logical object-function. When it is actually identified and distinguished by a thinking subject, this analytical object-function is disclosed or made patent. 
generating antinomies. 14 Sometimes the challenge is not to get out of the circle, but to get into it.

The following cluster of terms transcends the confines of the numerical aspect as such: simultaneity (at once), completedness, wholeness (totality), and the whole-parts relation.

Among 20th-century mathematicians the most prominent recognition of the spatial "home" of the terms wholeness and totality is found in the thought of Bernays. In the beginning of this article it has been noted that he recommends a distinction between the discrete and the continuous (Bernays, 1976:81). This conviction of Bernays is all the more significant in the light of the fact that he is fully acquainted with the arithmeticistic claims of modern analysis and set theory. He in fact radically questions the ideal of a complete arithmetization of mathematics. He unambiguously writes:

We have to concede that the classical foundation of the theory of real numbers by Cantor and Dedekind does not constitute a complete arithmetization of mathematics. It is anyway very doubtful whether a complete arithmetization of the idea of the continuum could be fully justified. The idea of the continuum is after all originally a geometric idea (Bernays, 1976:187-188). ${ }^{15}$

This acknowledgement of the geometric "descent" of the idea of continuity also serves another important purpose when it comes to an understanding of diverging mathematical schools of thought because it opens up an insight into the irreducibility of succession and at once (simultaneity). This distinction is particularly helpful in explaining the difference between the so-called potential infinite and the so-called actual infinite. On the basis of this distinction between succession and at once the irreducibility of the notion of a totality also surfaces. Hilbert introduces the difference between the potential and the actual (or genuine) infinite by using the example of the "totality (italics - DFMS) of the numbers $1,2,3,4, \ldots$ " which is

14 The classical example is Zeno's attempt to define movement in static spatial terms (see the preceding article on primitive terms in mathematics - Strauss, 2005a:515-534) - but doing that eliminated the meaning of motion.

15 "Zuzugeben ist, daß die klassische Begründung der Theorie der reellen Zahlen durch Cantor und Dedekind keine restlose Arithmetisierung bildet. Jedoch, es ist sehr zweifelhaft, ob eine restlose Arithmetisierung der Idee des Kontinuums voll gerecht werden kann. Die Idee des Kontinuums ist, jedenfalls ursprünglich, eine geometrische Idee." 
viewed as a unity that is given at once (completed). ${ }^{16}$ According to Lorenzen (1968:97) understanding real numbers with the aid of the actual infinite cannot camouflage its ties with space (geometry):

The overwhelming appearance of the actual infinite in modern mathematics is therefore only understandable if one includes geometry in one's treatment. ... The actual infinite contained in the modern concept of real numbers still reveals its descent (Herkunft) from geometry.

Lorenzen highlights the same assumption when he explains how real numbers are accounted for in terms of the actual infinite:

One imagines much rather the real numbers as all at once actually present - even every real number is thus represented as an infinite decimal fraction, as if the infinitely many figures (Ziffern) existed all at once ['alle auf einmal existierten'] (Lorenzen, 1972:163).

These modes of speech highlight the inevitability of employing terms with a spatial descent even when the aim is to proceed in numerical terms only. Lorenzen correctly points out that arithmetic as such does not provide any motivation for the introduction of the actual infinite (Lorenzen, 1972:159). The fundamental difference between arithmetic and analysis in its classical form, according to Körner, follows from the fact that the central concept of analysis, namely that of a real number, is defined with the aid of actual infinite totalities ("aktual unendlicher Gesamtheiten" - Körner, 1972:134). Without this supposition Cantor's proof on the non-denumerability of the real numbers collapses into denumerability. While rejecting the actual infinite, intuitionism interprets Cantor's diagonal proof of the nondenumerability of the real numbers in a constructive sense (cf. Heyting, 1971:40; Fraenkel et al., 1973:256, 272; Fraenkel, 1928: 239, note 1). However, in order to reach the conclusion of nondenumerability, every constructive interpretation fails - simply

16 "Will man in Kürze die neue Auffassung des Unendlichen, der Cantor Eingang verschafft hat, charakterisieren, so könnte man wohl sagen: in der Analysis haben wir es nur mit dem Unendlichkleinen und dem Unendlichengroßen als Limesbegriff, als etwas Werdendem, Entstehendem, Erzeugtem, d.h., wie man sagt, mit dem potentiellen Unendlichen zu tun. Aber das eigentlich Unendliche selbst ist dies nicht. Dieses haben wir z.B., wenn wir die Gesamtheit der Zahlen $1,2,3,4, \ldots$ selbst als eine fertige Einheit betrachten oder die Punkte einer Strecke als eine Gesamtheit von Dingen ansehen, die fertig vorliegt. Diese Art des Unendlichen wird als aktual unendlich bezeichnet" (Hilbert, 1925:167). 
because there is no constructive transition from the potential to the actual infinite (cf. Wolff, 1971).

\section{- Remark: Husserl's Philosophie der Aritmetik17}

In 1887 Edmund Husserl completed his habilitation dedicated to a psychological analysis of the concept of number - followed in 1891 by his extensive Philosophie der Arithmetik. In the latter work he connected the infinite both with the psychological nature of a collective synthesis (Husserl, 1970:64 ff.), and with the principle of succession (Husserl, 1970:220). He questioned the actual infinite in the light of the finiteness of arithmetic. He even planned a second volume of his Philosophie der Arithmetik, but eventually realised that he could not achieve his aim without using the actual infinite. L. Eley (in the Preface to Husserliana, Vol. XII) saw in this failure the reason why this second volume was never published. From the unpublished manuscripts it is nevertheless clear that Husserl did not succeed in giving a foundation to general arithmetic without the acceptance of the actual infinite (it indicates that he got stuck in classical analysis).

In the light of our preceding considerations it therefore seems impossible to develop set theory without "borrowing" key-elements from our basic intuition of space, in particular the (order of) at once and its factual correlate, wholesness or totality. 18

Of course Bernays did not have a theory of modal aspects at his disposal and therefore his approach did not have the possibility of explicitly articulating the intermodal connections between number and space. Nonetheless, formulations in his writings have been found approximating our idea of intermodal coherences. For example, instead of saying that a mathematical analysis of the meaning of number reveals an anticipation to the meaning of space, he explains that the idea of the continuum is a geometrical idea expressed by analysis in an arithmetical language. ${ }^{19}$

17 Edmund Husserl completed his habilitation in 1887 and published his study Philosophie der Aritmetik in 1891.

18 Since spatial subjects are extended their multiple parts exist all at once. This multiplicity is at the factual side of the spatial aspect a retrocipation to the meaning of number - i.e. multiple parts analogically reflect the meaning of number within space.

19 "Die Idee des Kontinuums ist, jedenfalls ursprünglich, eine geometrische Idee, welche durch die Analysis in arithmetischer Sprache ausgedrükt wird" (Bernays, 1976:74). 


\section{A deepened understanding of infinity}

It has already been pointed out that the most primitive meaning of infinity relates to the arithmetical time-order of succession. This order of succession appears on the law-side of the numerical aspect. It determines every infinitely proceeding sequence of numbers as well as the different operations on the law-side of the arithmetical aspect - operations such as addition, multiplication, subtraction, division, as well as the principle of induction - that can be disclosed by (non-theoretical as well as theoretical) mathematical thinking. The expression potential infinite lacks an immediate intuitive clarity. Therefore a suitable phrase capable of capturing the meaning of this most basic kind of infinity is to call it the successive infinite.

The Greeks already turned this kind of infinity infinite "inwards" for they discovered the infinite divisibility of continuity. In terms of the intermodal coherence between the aspects of number and space this infinite divisibility analogically (i.e. as a retrocipatory analogy) brings to expression the successive infinite on the law-side of the numerical aspect. The system of rational numbers (fractions), in turn, analogically (i.e. as an anticipatory analogy) reflects this infinite divisibility evinced at the factual side of the spatial aspect. Consequently, the rational numbers represent an anticipation to a retrocipation. 20

When, under the guidance of our theoretical (i.e. modally abstracting) insight into the meaning of the spatial order of simultaneity, the original modal meaning of the numerical time-order is disclosed, we encounter the regulatively deepened anticipatory idea of actual or completed infinity. Directed in an anticipatory way by the spatial order of simultaneity, any sequence of numbers may then be considered as if its infinite number of elements are present as a whole (totality) all at once.

In this context it is noteworthy that Hao Wang informs us that Kurt Gödel speaks of sets as being "quasi-spatial" and then adds that he is not sure whether Gödel would have said the "same thing of numbers" (Wang, 1988:202). This mode of speech is in line with our 
suggestion that the undefined term member of employed in Zermelo-Fraenkel set theory actually gives shelter to the totality feature of continuity. The implication is that set theory (in an anticipating way) indeed depends on "something spatial".

This implication also confirms the unbreakable coherence between the law-side and the factual side of the numerical and the spatial aspects. The modal anticipation from the numerical time-order to the spatial time-order must therefore have its correlate at the factual side. At the factual side of the numerical aspect we find the sequence of natural numbers and integers (expressing the primitive meaning of numerical discreteness). Introducing the dense set of rational numbers manifests - as an anticipation to a retrocipation the semi-disclosed meaning of number.

When we employ the anticipation on the law-side of the numerical aspect to the law-side of the spatial aspect we encounter the intermodal foundation of the notion of actual infinity - although the basic intuitions at play suggest a more suitable designation for this kind of infinity. Before the above-mentioned alternative designation of the actual infinite is, however, explained in more detail, the as if nature of this deepened notion of infinity is in need of clarification.

The anticipation from number to space on the law-side determines the multiplicity of natural numbers correlated with it - as an infinite totality. The same applies to integers and rational numbers for when the idea of the actual infinite is employed they can be considered as if they are present as completed (though infinite) wholes or totalities.

\section{- Remark: As if: The actual infinite as a regulative hypothesis}

Vaihinger developed a whole philosophy of the as if (Die Philosophie $\operatorname{des} A / s \mathrm{Ob}$ ), in which he tries to demonstrate that certain fictions may be used positively by various academic disciplines in spite of the fact that in themselves they are considered to be internally antinomic. The infinite (whether infinitely large or infinitely small), is seen by Vaihinger as an example of a necessary and fruitful fiction (cf. Vaihinger, 1922:87 ff.; 530).

Ludwig Fischer presents a more elaborate mathematical explanation of this notion of a fiction. In general he argues: 
The definition of an irrational number by means of a formation rule always involves an 'endless', i.e. unfinished process. Supposing that the number is thus given, then one has to think of it as the completion (Vollendung) of this unfinished process. Only in this ... the internally antinomic (in sich widerspruchsvolle) and fictitious character of those numbers are already founded (Fischer, 1933:113-114)

Without the aid of a prior analysis of the modal meaning of number and space, this conclusion is almost inevitable. Vaihinger and especially Fischer simply use the number concept of uncompleted infinity (the successive infinite) as a standard to judge the (onto-) logical status of the actual infinite. Surely, within the closed (not yet deepened) meaning of the numerical aspect, merely determined by the arithmetical time-order of unfinished succession, the notion of an actual infinite multiplicity is indeed self-contradictory.

However, the idea of the actual infinite transcends the limits of this concept of the successive infinite since, in a regulative way, it refers to the core meaning of the spatial aspect. In an anticipatory sense the actual infinite hypothetically uses the spatial time-order of simultaneity, the all viewed as being present at once.

Paul Lorenzen did understand something of this hypothetical spatial anticipation, for he remarks that the meaning of actual infinity as attached to the all shows the employment of a fiction - "the fiction, as if infinitely many numbers are given" (Lorenzen, 1952:593). In this case too, we see that the as if is ruled out, or at least disqualified as something fictitious, with an implicit appeal to the primitive meaning of number only. But as long as one sticks to the notion of a process, one implicitly merely applies the yardstick of the successive infinite in order to judge the actual infinite.

Paul Bernays also acknowledged the essential hypothetical character of the opened-up meaning of number. But in the absence of an articulated analysis of the intermodal meaning coherence present between number and space he was unable to fully explore the meaning of this anticipatory hypothesis:

The position at which we have arrived in connection with the theory of the infinite may be seen as a kind of the philosophy of the 'as if'. Nevertheless, it distinguishes itself from the thus named philosophy of Vaihinger fundamentally by emphasizing the consistency and trustworthiness of this formation of ideas, where 
Vaihinger considered the demand for consistency as a prejudice ... (Bernays, 1976:60).

Although the deepened meaning of infinity is sometimes designated by the phrase completed infinity, this habit may be misleading. If succession and simultaneity are mutually irreducible, then the idea of an infinite totality cannot simply be seen as the completion of an infinite succession. Where Dummett refers to the classical treatment of infinite structures "as if they could be completed and then surveyed in their totality" he errs in equating this "infinite totality" with "the entire output of an infinite process" (Dummett, 1978:56). The idea of an infinite totality transcends the concept of the successive infinite.

Cantor explicitly describes the actual infinite as a constant quantity, "firm and determined in all its parts" (Cantor, 1962:401). Throughout the history of Western philosophy and mathematics, all supporters of the idea of actual infinity implicitly or explicitly employed some or other form of the spatial order of simultaneity. What should have been used as an anticipatory regulative hypothesis (the idea of actual infinity), was often (since Augustine) reserved for God or an "eternal being", accredited with the ability to oversee any infinite multiplicity all at once.

This anticipatory regulative hypothesis of actual infinity does not cancel or eliminate the original modal meaning of number, but only deepens it under the guidance of theoretical thought.

Perhaps also in this respect it would be helpful to introduce new terms for this well-known expression. Instead of speaking of the actual infinite we may prefer to talk of the at once infinite. An awareness of this terminology already surfaced in the disputes of the early 14th century regarding the supposed infinity of God. ${ }^{21}$

These new expressions relate directly to our basic numerical and spatial intuitions, viz. our awareness of succession and simultaneity - and their mutual irreducibility finds its foundation in the irreducibility of the aspects of number and space. 22

21 Compare the expressions infinitum successivum and infinitum simultaneum (Maier, 1964:77-79).

22 Dooyeweerd did not accept the idea of the at once infinite (actual infinity) owing to the fact that he was strongly influenced by the intuitionistic mathematicians 
A truly deepened and disclosed account of the real numbers cannot be given without the support of the at once infinite. That this anticipatory coherence between number and space always functioned prominently in a deepened account of the real numbers, can be indicated from many sources. It will suffice to mention only one in this context. Before doing that we have to return briefly to the relationship between mathematics and logic.

\section{Mathematics and logic}

The logicistic attempt to deduce the meaning of number from the logical mode turned out to be circular in nature. If the meaning of analysis, however, presupposes the original quantitative meaning of unity and multiplicity, then it appears to be strange that we still have to concede that the discipline of mathematics is in need of a logical foundation.

Cassirer implicitly approaches this problem in terms of the numerical analogy within the logical-analytical mode. His question is that it is not understandable why one only accepts logical identity and difference, which enter into the set concept as necessary elements, as such basic functions, but that one does not do the same with regard to numerical unity and difference as well. He claims that a truly satisfactory deduction of the one from the other is also not achieved by set theory, which entails a persistent suspicion that all similar attempts will continue to harbour a concealed epistemological circle.23

Yet, although it is true that the meaning of analysis presupposes the meaning of number, the (theoretical) analysis of the meaning of number remains a thought act that is qualified by the logical aspect. For this reason the discipline of logic occupies a foundational role with respect to all disciplines, including mathematics.

Brouwer and Weyl in this regard (cf. Dooyeweerd, 1996-I:98-99, footnote 1; and Dooyeweerd, 1996-II:340, footnote 1).

23 "In der Tat ist nicht einzusehen, warum man lediglich logische Identität und Verschiedenheit, die als notwendige Momente in den Mengenbegriff eingehen, als solche Urfunktionen gelten lassen und nicht auch die numerische einheit und den numersichen Unterschied von Anfang an in diesen Kreis aufnehmen will. Eine wirklich befriedigende Herleitung des einen aus dem anderen ist auch der mengentheoretischen Auffassung nicht gelungen, und der Verdacht eines versteckten erkenntnistheoretischen Zirkels blieb gegenüber allen Versuchen, die in dieser Richtung gemacht werden, immer bestehen" (Cassirer, 1957:7374). 
These systematic distinctions pertaining to the uniqueness and mutual coherence of number and space will now be made fruitful for an understanding of arithmeticism and its shortcomings in modern mathematics.

\section{The circularity entailed in set-theoretical attempts to arithmetise continuity}

The nuclear meaning of space is indefinable. If one tries to define what is indefinable two equally objectionable options are open:

- either one ends up with a tautology - coherence, being connected, and so on, are all synonymous terms for continuity; or, even worse,

- one becomes a victim of (antinomic) reduction, i.e. one tries to reduce what is indefinable to something familiar but distinct from what is "defined".

While the idea is ancient, modern Cantorian set theory again has come up with the conviction that a spatial subject such as a particular line simply is an infinite (technically a non-denumerable infinite) set of points.

If the points constituting the one-dimensional continuity of a line were themselves extended in any sense, the absurd implication that the continuity of every point is again constituted by "smaller points" than the first type would have to follow. But then each one of these "smaller points" of necessity would still be extended. Continuing this argument ad infinitum unmasks the absurd notion of ever "smaller" points, i.e. points with an ever-diminishing "size". In reality such "diminishing" points do not at all refer to genuine points, since they simply reflect the primitive meaning of continuous extension. And we have noted that spatial continuity is infinitely divisible. Points like these entail the circularity that they are meant to build up space out of space.

Anything that has factual spatial extension has a subject-function in the spatial aspect (such as a chair) or is a modal subject in space (such as a line, a surface, and so forth). Within space a point is, however, always dependent on a spatial subject for it is not extended.24 The length, surface or volume of a point is always zero

24 We are now in a better position to explain the structural meaning of the three undefined terms introduced by Hilbert in his axiomatisation of geometry in 1899. 
- a point is simply not extended in any dimension. If the measure of one point is zero, then any number of points would still have a zeromeasure. Even a denumerable infinite set of points would never constitute any positive distance, since distance presupposes an extended subject.

Grünbaum combined insights from the theory of point-sets (founded by Cantor) with general topological notions and with basic elements in modern dimension theory and measure theory in order to arrive at an apparently consistent conception of the extended linear continuum as an aggregate of unextended elements (see Grünbaum, 1952:288 ff.). From his analysis it is clear that he actually had "unextended unit point-sets" in mind and not simply a set of "unextended points" (Grünbaum, 1952:295). Initially he starts with a non-metrical topological description and then, later on, introduces a suitable metric normally used for Euclidean spaces (point-sets). The decisive presupposition of this analysis is given in the acceptance of the linear Cantorean continuum (arranged in an order of magnitude, i.e. the class of all real numbers) (cf. Grünbaum, 1952:296).

On the basis of certain distance axioms, the real function $d(x, y)$ (called the distance of the points $x, y$ which have the coordinates $\mathrm{x}_{\mathrm{i}}, \mathrm{y}_{\mathrm{i}}$ ) is used to define the length of a point-set constituting a finite interval on a straight line between two fixed points (the number of this distance is its length). For example, the length of a finite interval $(a, b)$ is defined as the non-negative quantity $b-a$ (disregarding the issue about the interval's being closed, open, or half-open). In the limiting case of $a=b$, the interval is called degenerate with length zero (in this case we have a set containing a single point) (cf. Grünbaum, 1952:296).

Furthermore, division as an operation is only defined on sets and not on their elements, implying that the divisibility of finite sets consists of the formation of proper non-empty subsets of these (surely, the degenerate interval is indivisible by virtue of its lack of a subset of the required kind) (Grünbaum, 1952:301). Finally, the following two

These terms instantiate the spatial subject-object relation at the factual side of the spatial aspect. The term line represents the factual subject-side (factual, one-dimensional spatial extension); the term point represents the factual objectside (always dependent upon an extended spatial subject); while the relation of dependence of the latter upon the former (i.e., the spatial subject-object relation) is represented by the relational term lies on. 
propositions are asserted and are considered to the perfectly consistent:

1. The line and intervals in it are infinitely divisible; and

2. The line and intervals in it are each a union of indivisible degenerate intervals (Grünbaum, 1952:301).

When Grünbaum's analysis is met with our characterisation of the actual infinite (the at once infinite), the circularity of his whole approach is clearly seen. On the basis of the regulative hypothesis of the at once infinite, not only the set of real numbers but also the number of line segments having a common end point could be considered as non-denumerable infinite totalities. In the latter case (i.e. in the case of a group of line segments), we may identify, within the modal structure of space, a retrocipation to an anticipation (a mirror-image of the structure of the system of rational numbers). This retrocipation to an anticipation ultimately underlies Grünbaum's statement that "the Cantorean line can be said to be already actually infinitely divided" (Grünbaum, 1952:300).

The objection that any denumerable sum of degenerate intervals (with zero-length) must have a length of zero, does not invalidate Grünbaum's claim that a positive interval is the union of a continuum of degenerate intervals, for in the latter case we are confronted with a non-denumerable number of degenerate intervals. Surely, if we cannot enumerate them, we cannot add them in order to form their sum.

In order to understand the impasse entailed in Grünbaum's account we only have to note the fact that non-denumerability presupposes the use of the at once infinite, as well as the fact that the at once infinite presupposes the spatial time-order of at once. As soon as this is realised, it becomes clear that Grünbaum's argumentation is the victim of the following vicious circle. Spatial continuity could be reduced to number if and only if the at once infinite is used - but that presupposes what is supposed to be reduced, namely the (irreducibile) spatial time-order of at once. Space can therefore be reduced to number if and only if it is irreducible to number! 25

25 Grünbaum had to concede: "The consistency of the metrical analysis which I have given depends crucially on the non-denumerability of the infinite point-sets constituting the intervals on the line" (Grünbaum, 1952:302). He, however, did not realise that one can only arrive at non-denumerability by accepting the at once infinite. and thus by presupposing the irreducibility of space. 
Another consideration is quite enlightening in this context. 26 Cantor refers to the relation that exists between his view of a perfect set and Dedekind's cut theorem (Cantor, 1962:194). In a striking way Böhme then shows that Cantor's definition of the continuum (as a perfectly coherent set) contains two stipulations that in fact conform to the two requirements of Aristotle's definition of a continuum, namely coherence and a characteristic that ensures the existence of points of division for an infinity of them (see Böhme, 1966:309). By allowing only Dedekind cuts as divisions, Böhme justifies his statement by indicating that a Dedekind cut considers one point twice (the largest and the smallest ones are identical) and that Cantor's notion of coherence reflects the Aristotelian view of the infinite divisibility of a continuum (see Böhme, 1966:309).

What is remarkable is that the Cantor-Dedekind description of continuity is dependent upon the use of the actual infinite (the actually infinite set of real numbers), but nonetheless meets the two requirements for a continuum set by Aristotle, in spite of the fact that Aristotle explicitly rejects the actual infinite. He only recognises potential infinity.

\section{- Did Aristotle use the actual infinite implicitly}

The question thus remains: Did Aristotle use the actual infinite implicitly, or is the Cantor-Dedekind definition in the last instance not purely arithmetically founded?

This seemingly perplexing situation is immediately clarified on the basis of our analysis of the intermodal coherence between number and space. We have established that the original spatial whole-parts relation indeed has its foundation in the numerical time-order of succession in that it displays the primitive meaning of infinity as endlessness. This in turn highlights the infinite or endless divisibility of spatial continuity. 27 If one restricts oneself to this original meaning of the spatial aspect (without, in addition, considering the opened-up meaning of the foundational aspect of number), as Aristotle implicitly did (which is understandable in the light of the geometrisation of Greek mathematics), then no meaning could be attached to the notion of actual infinity. This explains the relative correctness present in the claim (put forward by Aristotle, Kant and many others

27 This feature manifests the retrocipation at the factual side of the spatial aspect to the law-side of the numerical aspect. 
in the history of philosophy and mathematics) that a line is not divided in the sense of the actual infinite (at once infinite), but only divisible in the sense of the potential infinite (the successive infinite). It is relatively correct, because the foundational meaning of number (analogically reflected in the multiplicity of successive spatial divisions) is not itself as yet opened up by the anticipatory hypothesis of the at once infinite (directing the meaning of number, under the guidance of theoretical thinking, to the modal meaning of space).

This is, however, exactly what Cantor did - he effectively used this anticipatory meaning of number in his description of a perfectly coherent set of real numbers (taken in their linear order), without realising, however, that implicitly his use of the at once infinite presupposes the primitive and irreducible spatial order of simultaneity. But given this disclosed approach, it is no longer possible to argue against the actually infinite dividedness of a line on the basis of its infinite divisibility. The notion of endless divisibility, employing the number-concept of the successive infinite, may be deepened with the foundational aid of the opened-up numerical use of the number-idea of actual infinity. Consequently, the diverging approaches to continuity present in the thought of Aristotle and Cantor - in spite of their formal agreement concerning the two mentioned criteria for continuity - may be summarised as follows:

\section{Aristotle and Cantor's characterisation of continuity}

Both Aristotle and Cantor characterise continuity, but each one chooses his own view-point - Aristotle's angle of approach is the spatial aspect (which does not necessarily need the at once infinite), whereas Cantor's perspective uses the numerical anticipation to space (an approach which does need the at once infinite).

Intuitionistic mathematics is much closer to Aristotle because it approximates real numbers by means of successive rational intervals - compare Brouwer's notion of choice sequences and successive, partially overlapping parts (Fraenkel et al., 1973:256).

\section{- The irreducibility of the modal meaning of space to that of number}

The preceding analysis enables us to claim that the irreducibility of the spatial time-order of simultaneity to the numerical time-order of succession ultimately rests on the irreducibility of the modal 
meaning of space to that of number. From this claim it directly follows that the spatial whole-parts relation, determined by the spatial order of simultaneity, is irreducible as well, and it also explains why the typical totality character of the continuum renders the attempted purely arithmetical "definition" of continuity circular. Our argumentation therefore has indicated that the modal meaning of space, qualified by the primitive meaning-nucleus of continuous extension, 28 not only implies that this meaning-nucleus of space is irreducible to number, but also that the spatial order of simultaneity on the law-side, as well as the whole-parts relation at the factual side of the spatial aspect, ultimately are irreducible.

Although he did not pay attention to the law-side of the spatial aspect (obviously because he did not dispose over an articulated meaning-analysis of the structure of number and space), we have noted in the preceding article (Strauss, 2005a:515-534; see note 19) that Paul Bernays does appreciate the irreducibility of the spatial whole-parts relation (the totality feature of spatial continuity) (Bernays, 1976:74).

The property of being a totality "undeniably belongs to the geometric idea of the continuum. And it is this characteristic which resists a complete arithmetization of the continuum". 29

Bernays's deeply felt reaction against the mistaken and one-sided nature of modern arithmeticism is best seen from his following words:

The arithmetizing monism in mathematics is an arbitrary thesis. The claim that the field of investigation of mathematics purely emerges from the representation of number is not at all shown. Much rather, it is presumably the case that concepts such as a continuous curve and an area, and in particular the concepts used in topology, are not reducible to notions of number (Zahlvorstellungen) (Bernays, 1976:188).

28 Expressing itself on the law-side as an order of simultaneity and at the factual side as dimensionally determined extension - with or without a defined metric.

29 "Und es ist auch dieser Charakter, der einer vollkommenen Arithmetisierung des Kontinuums entgegensteht” (Bernays, 1976:74). 


\section{Concluding assessment}

Although continuity belongs to the core meaning of the spatial aspect, and in this role qualifies the retrocipatory analogies to number within this aspect, the meaning of spatial continuity expresses itself in its coherence with the (foundational) meaning of number.

The divergence of intuitionistic and (axiomatic-) formalistic mathematics briefly explained at the beginning of this article, ultimately boils down to alternative philosophical views of the relationship between number and space.

- Intuitionistic mathematics restricts itself to the use of the successive infinite, and in doing it at most produced a semidisclosed analysis of the real numbers.

- Axiomatic formalism, in contrast, did take the step to explore and employ the at once infinite, but did not realise that this move presupposes the irreducibility of the spatial time-order of at once.

At the same time this analysis makes it possible for us to defend the thesis that modern mathematical set theory ought to be characterised as a spatially deepened theory of number. Bernays (1976:74) phrased this (above-mentioned) characterisation as follows: "The idea of the continuum is a geometrical idea which analysis expresses in terms of arithmetic".30

Not realising this, the spatially deepened nature of set theory causes the vicious circle entailed in all attempts to argue for a complete reduction of space to number on the basis of a theory employing the numerical anticipation to space (i.e. by accepting the at once infinite). In opposition to the attempt of Greek mathematics to reduce number to space and the modern pursuit to arithmetise space, we have now articulated in more detail the alternative view that acknowledges the uniqueness and mutual coherence of number and space.

A topological description of continuity abstracts from any given metric. 


\section{List of references}

BERNAYS, P. 1976. Abhandlungen zur Philosophie der Mathemetik. Darmstadt: Wissenschaftliche Buchgesellschaft.

BETH, W. 1965. Mathematical thought. New York: Reidel.

BÖHME, G. 1966. Unendlichkeit und Kontinuität. Philosophia Naturalis, 11:403317.

CANTOR, G. 1962 [1932]. Gesammelte Abhandlungen Mathematischen und Philosophischen Inhalts. Hildesheim: Olms.

CASSIRER, E. 1907. Kant und die modernen Mathematik: mit Bezug auf Bertrand Russels und Louis Couturats Werke über die Prinzipien der Mathematik. Kant-Studien, 12:1-49.

CASSIRER, E. 1910. Substanzbegriff und Funktionsbegriff. Berlin: s.n. (Reprinted: Darmstadt: Wissenschaftliche Buchgesellschaft.)

CASSIRER, E. 1953. Substance and function. New York: Dover Edition. (First edition of the English translation of Substanzbegriff und Funktionsbegriff: 1923.)

CASSIRER, E. 1957. Das Erkenntnisproblem in der Philosophie und Wissenschaft der neueren Zeit. Stuttgart: Kohlhammer.

DESCARTES, R. 1965a. A discourse on method, meditations and principles. Tr. by John Vertich. Intoduced by A.D. Lindsay. London: Everyman's Library.

DESCARTES, R. 1965b. The principles of philosophy. (In Descartes, R. A discourse on method, meditations and principles. Tr. by John Vertich. Intoduced by A.D. Lindsay. London: Everyman's Library.)

DOOYEWEERD, H. 1996. A new critique of theoretical thought. Series A (Volumes I-IV) of The collected works of Herman Dooyeweerd. General editor D.F.M. Strauss. Lewiston: Mellen.

DUMMETT, M.A.E. 1978. Elements of intuitionism. Oxford: Clarendon.

DUMMETT, M.A.E. 1995. Frege, philosophy of mathematics. Cambridge: Harvard University Press.

ELEY, L. 1970. Preface. (In Husserliana. Band VI. The Hague: Nijhoff. p. 1329.)

FISCHER, L. 1933. Die Grundlagen der Philosophie und der Mathematik. Leipzig: s.n.

FRAENKEL, A. 1928. Einleitung in die Mengenlehre. Berlin: Springer.

FRAENKEL, A., BAR-HILLEL, Y., LEVY, A. \& VAN DALEN, D. 1973. Foundations of set theory. Second revised edition. Amsterdam: North Holland.

FREGE, G. 1934 [1884]. Grundlagen der Arithmetik. Breslau: Marcus.

GRÜNBAUM, A. 1952. A consistent conception of the extended linear continuum as an aggregate of unextended elements. Philosophy of Science, 19(2):288-306.

HEYTING, A.T.A. 1949. Spanningen in de Wiskunde. Groningen: Noordhoff.

HEYTING, A.T.A. 1971. Intuitionism: an introduction. Third revised edition. Amsterdam: North-Holland.

HILBERT, D. 1925. Über das Unendliche. Mathematische Annalen, 95:161-190.

HILBERT, D. 1930. Naturerkennen und Logik. (In Hilbert, D. Gesammelte Abhandlungen. 3. 2. Aufl. Berlin: Springer. p. 378-387.)

HUSSERL, E. 1970 [1891]. Philosophie der Arithmetik. (In Husserliana. Vol. XII. The Hague: Nijhof.) 
KANT, I. 1787 [1781]. Kritik der reinen Vernunft. (Hamburg: Felix Meiner Edition, 1967).

KÖRNER, S. 1972. Mathematik als die Wissenschaft formaler Systeme: Exposition. (In Meschkowski, H., Red. Grundlagen der modernen Mathematik. Darmstadt: Wissenschaftliche Buchgesellschaft.)

LORENZEN, P. 1952. Ueber die Widerspruchfreiheit des Unendlichkeitsbegriffes. Studium Generale, Zeitschrift für die Einheit der Wissenschaft und im Zusammenhang ihrer Begriffsbildungen und Forschungsmethoden, 10:591-594.

LORENZEN, P. 1972. Das Aktual-Unendliche in der Mathematik. (In Meschkowski, H., Red. Grundlagen der modernen Mathematik. Darmstadt: Wissenschaftliche Buchgesellschaft. p. 157-165.)

MADDY, P. 1997. Naturalism in mathematics. Oxford: Clarendon.

MAIER, A. 1964. Diskussion über das Aktuell Unendlichen in der ersten Hälfte des 14. Jahrhunderts. (In Maier, A. Ausgehendes Mittelalter. Vol. I. Rome: Edizioni di Storia e letteratura. p. 41-85.)

MESCHKOWSKI, H., Red. 1972. Grundlagen der modernen Mathematik. Darmstadt: Wissenschaftliche Buchgesellschaft.

MOORE, A.W. 1990. The infinite. London: Routledge.

RUCKER, R. 1982. Infinity and the mind: the science and philosophy of the infinite. Boston: Birkhäuser.

SALMON, W., ed. 2001 [1970]. Zeno's paradoxes. New York: Bobs-Merrill.

SHAPIRO, S. 1997. Philosophy of mathematics: structure and ontology. Oxford: Oxford University Press.

SHAPIRO, S. 2005a. The Oxford handbook of philosophy of mahematics and logic. Oxford: Oxford University Press.

SHAPIRO, S. 2005b. Philosophy of mathematics and its logic. (In Shapiro, S. The Oxford handbook of philosophy of mathematics and logic. Oxford: Oxford University Press. p. 3-28.)

STEGMÜLLER, W. 1965. Glauben, Wissen und Erkennen: das Universalienproblem einst und jetzt. Darmstadt: Wissenschaftliche Buchgesellschaft.

STEGMÜLLER, W. 1970. Main currents in contemporary German, British and American philosophy. Dordrecht-Holland: Reidel.

STRAUSS, D.F.M. 2002. Philosophical reflections on continuity. Acta Academica, 34(3):1-32.

STRAUSS, D.F.M. 2003. Frege's attack on "abstraction" and his defense of the "applicability" of arithmetic (as part of logic). South African Journal of Philosophy, 22(1):63-80.

STRAUSS, D.F.M. 2005a. Accounting for primitive terms in mathematics. Koers, 70(3):515-534.

STRAUSS, D.F.M. 2005b. Discerning similarities: concept and word at the intersection of analogy and metaphor. Acta Academica, 37(2):1-20.

VAIHINGER, H. 1922. Die Philosophie des Als Ob. 8. Aufl. Leibzig: Meiner. (Translated by C.K. Ogden (1949). The Philosophy of "As If". London: Routledge \& Kegan Paul.)

WANG, H 1988. Reflections on Gödel. Cambridge: MIT.

WOLFF, K. 1971. Zur Problematik der absoluten Überabzählbarkeit. Philosophia Naturalis, 13:399-404. 


\section{Key concepts:}

analogical basic concepts

infinity

irreducibility of number and space

modal aspects

Kernbegrippe:

analogiese grondbegrippe

modale aspekte

oneindigheid

onherleibaarheid van getal en ruimte 
